\title{
INTEGRATED IMAGING APPROACHES SUPPORTING THE EXCAVATION ACTIVITIES. MULTI-SCALE GEOSPATIAL DOCUMENTATION IN HIERAPOLIS (TK).
}

\author{
A.Spanò ${ }^{1 *}$, F. Chiabrando ${ }^{1}$, G. Sammartano ${ }^{1}$, L. Teppati Losè ${ }^{1}$ \\ 1 Politecnico di Torino, Dipartimento di Architettura e Design - Lab G4CH \\ (filiberto.chiabrando, giulia.sammartano, antonia.spano, lorenzo.teppati)@ polito.it
}

Commission II, WG II/8 KEY WORDS: multi-scale model, $\mathrm{CH}$, data integration, UAV photogrammetry, archaeological documentation, rapid mapping,
excavation monitoring

\begin{abstract}
:
The paper focuses on the exploration of the suitability and the discretization of applicability issues about advanced surveying integrated techniques, mainly based on image-based approaches compared and integrated to range-based ones that have been developed with the use of the cutting-edge solutions tested on field. The investigated techniques integrate both technological devices for 3D data acquisition and thus editing and management systems to handle metric models and multi-dimensional data in a geospatial perspective, in order to innovate and speed up the extraction of information during the archaeological excavation activities. These factors, have been experienced in the outstanding site of the Hierapolis of Phrygia ancient city (Turkey), downstream the 2017 surveying missions, in order to produce high-scale metric deliverables in terms of high-detailed Digital Surface Models (DSM), 3D continuous surface models and high-resolution orthoimages products. In particular, the potentialities in the use of UAV platforms for low altitude acquisitions in aerial photogrammetric approach, together with terrestrial panoramic acquisitions (Trimble V10 imaging rover), have been investigated with a comparison toward consolidated Terrestrial Laser Scanning (TLS) measurements.

One of the main purposes of the paper is to evaluate the results offered by the technologies used independently and using integrated approaches. A section of the study in fact, is specifically dedicated to experimenting the union of different sensor dense clouds: both dense clouds derived from UAV have been integrated with terrestrial Lidar clouds, to evaluate their fusion. Different test cases have been considered, representing typical situations that can be encountered in archaeological sites.
\end{abstract}

\section{INTRODUCTION}

The proposed study intends to present some operational best practices of the application of latest Geomatics methodological approaches in metric documentation, facing the multi-scale complexity of the archaeological excavation and supporting the multidisciplinary research activities, typical of the ancient sites studies and long-term investigations. Within the current dynamics of research on digital documentation already or partially disseminated in the archaeological survey methods (Fiorillo et al., 2013; Balletti et al., 2015; Sauerbier \& Eisenbeiss, 2010; Dell'Unto, 2014) the presented contribution will propose a focus on advanced mapping technologies oriented to sustain and metrically control the reading of stratified complexes and spaces in excavated contexts, particularly connected with landscape.

The fundamental contribution is retrieved in the multi-scale integration of the terrestrial and the aerial data inputs from rapid mapping and low-cost solutions, both in 3-dimensions (building archaeology) or with a prevalent planar development (archaeological excavation). These methods and techniques have been considered, according to the archaeological demands about multi-scale documentation, with two main aims: firstly, the support to the documentation of the landscape areas that have been subjected to extended investigations in a larger scale of their territorial extension. Then, for helping the analyses aimed at ancient structures interpretation or focused on specific excavation operations in the large-scale dimension (stratigraphic analysis, geophysics prospection, archaeometry examinations, etc), as is reported as well in Adamopoulos et al. 2017, Katsianis et al. 2008, Drap et al. 2012.

These aspects have been tackled in some of the areas recently investigated from the Italian Archaeological Mission, where the
Geomatics applied research has been aligned and integrated into a multi-faceted project of joint research addresses: the Multidisciplinary approach to Hierapolis of Phrygia studies that is an Italian relevant research project founded in 2016 (PRIN2015). The project is devoted to the research on the integrated approaches in archaeological studies of ancient urban heritage in Minor Asia between late Hellenism and Byzantine age. It is concerning the dynamics underlying the evolution of the sacred sites landscape, the inhabiting settlements types, the necropolis areas, the hydric resources distribution, the productive systems localization. In the framework of this project, several acquisitions have been performed in the archaeological site of Hierapolis; in the present paper the products connected to the metric documentation achieved on three different areas with a depth analysis and evaluation are presented.

The issues related with the $3 \mathrm{D}$ documentation of these areas will be discussed, triggering some reasoning about the multi-scale aspects and constraints in the deployment of multi-sensors technological approach to the archaeological investigation. Thus, the delivery of the suitable metric products for the spatiotemporal organization and management of the data, revolves around the archaeological excavation needs and was organized in a proposed tailored workflow.

\section{RAPID MAPPING SYSTEMS FOR ARCHAEOLOGICAL RESEARCH NEEDS}

The documentation of the cultural heritage has undergone an increasingly peculiar process of specialization in recent years, in parallel with the increasingly complex and articulated needs of the processes of conservation and heritage valorisation. Among the crucial points of the relevant needs of documentation we can 
consider the objective to obtain results quickly and efficiently, with less waste of resources and therefore in a sustainable way compared to the whole activity of knowledge conservation and transmission of heritage to future generations. Effectiveness and sustainability are meanings that have important implications on the usability of survey products and documentation, as the multidisciplinary scenario involved in the study processes requires flexibility to satisfy many different needs. (Sammartano 2018).

Several published papers report to what extent UAV photogrammetry has been affirmed in the field of rapid mapping systems, for a numerous series of reasons: because you can bring objects closer and document difficult areas as well (Xiao et. al 2012; Chiabrando et al. 2017a). Moreover, the recent use of oblique images, already known in airplane systems (Höhle, 2008) allow to improve the knowledge of the surveyed object with different non-conventional point of view. Furthermore, the possibility of correctly reshaping and modelling even the façades of buildings has considerably increased the documentation capabilities of UAV, since the huge availability of different solutions (fixed wing and multi-rotor), with different low-cost cameras (Feifei et al. 2012), have allowed for effective results in many different application sectors. Obviously, the recent statements are mainly due to the use of computer vision algorithms and their implementation in the most common softwares (Szeliski, 2010).

Archaeological research can greatly benefit from the use of UAV photogrammetry, mainly due to the possibility of generating models and metric products at the scale of landscape and of detailed ruins, and also for reasons related to the need to detect the upstanding structures of buildings, in the same way of the architectural complexes (Ruiz Sabina et al., 2015; Georgopoulos et al., 2016; Balletti et al. 2015, Chiabrando et.al. 2017b).

Close range acquisition performed by UAV, on the other side, can offer a powerful solution to the excavation monitoring. The contribution in intra-site documentation is not as much considered as other purposes in previous research; for this reason, point clouds and other metric products should be evaluated to figure out if they have to be validated for a correct geometric characterization of the excavation sections and layered features, according to the required scale.

Additionally, from the terrestrial point of view, new rapid mapping solutions have appeared on the market in the domain of range base (Tucci et al. 2018) and image base systems; the image base one has been investigated in the archaeological area of Hierapolis and reported in the present paper. In detail the more consolidated photogrammetric approach has been flanked by a rapid image-base solutions aimed to the documentation of the excavation: the Imaging Rover Trimble V10 (IR). The system was tested in and the collected data were processed and compared with more consolidated techniques.

The main idea of the system is connected to spherical and panoramic cameras that have a consolidated tradition in the domain of photogrammetric processing. Their advantageous use in the field of $\mathrm{CH}$ documentation and survey, based on rigorous geometric principles, has been highlighted by the studies of Fangi. (Fangi 2007; Fangi et al. 2008). Recent experiences that have tested the V10 have found an accuracy of the results obtained comparable with those obtainable by close range photogrammetry (Baiocchi et al., 2017) even by checking the position of control points measured by total station (Cera \& Campi 2017)

Both the aerial and terrestrial techniques have been deeply compared with well-known techniques in order to stress the possibility to use this system both for operators involved in the archaeological excavation contexts and to evaluate the chance to navigate DSM, orthoimages, or other metric models with the aim to continue to read and interpret the excavation site even not directly on the field.

\section{TEST SITES AND GENERAL SURVEY FRAMEWORK}

\subsection{Test sites}

Three areas of interest representing typical situations that can be encountered in archaeological sites, with the following main characteristic have been selected: excavation areas with prevailing planimetric development (a), excavation areas with not very high structures, for which the relationship with the urban and natural context is fundamental (b), excavation areas located within monumental buildings in which considerable height masonries are preserved (c).

- (a) Phrygian village (or necropolis?) A pre-hellenistic set of evidences connected to the Phrygian period of the site, currently under investigation. The complex (which functions and organisation are still not totally clarified yet) is located in the north area above the northern necropolis and was discovered during some works related to enhancement of some buildings for the reception of tourists (Fig. 1, above left);

- (b) Tub for textile dyeing. A structure devoted to the textiles dyeing, belonging to a set of widespread productive activities far from the dense settlements. It is placed in the northern part of the city, in the eastern area of the Necropolis characterized by a rich transformation of the urban landscape by the peculiar water supply system made of channels network (Fig.1 above right);

(c) The nymphaeum of the Apollo sanctuary. The monumental building is located in the central area of the city. It is a complex and stratified group of evidences under investigation. It has been studied and documented for a long time to disclose the dynamics underlying its origins and its relationship with the sacred area devoted to the Apollo oracular cult. Although the nymphaeum was dated to the III century A.D., his origin during a period of intense construction works makes his excavation and study particularly relevant to reconstruct the events of an age of transition to the Christian era (Fig. 1, below). (Semeraro 2012)

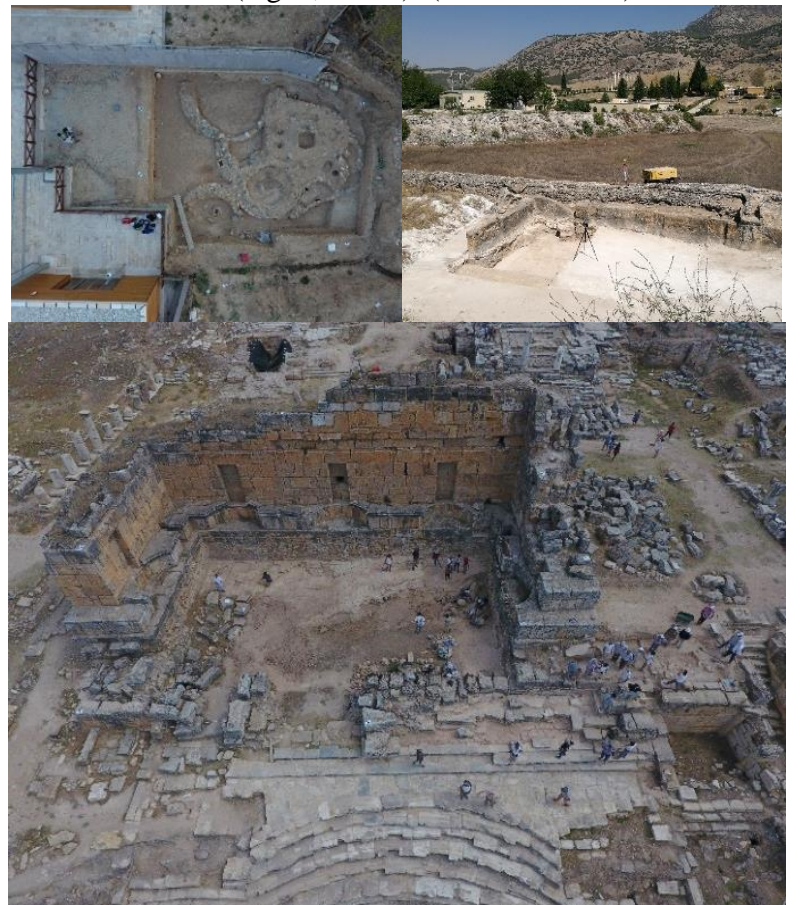

Figure 1. (above left) A nadir view of the Phrygian village site, wedged between the reception and conveying facilities of tourists. (above right) The basin for textiles dyeing, leaning against one of the limestone channels formed with the human intent to distribute the water in the city. (below) Bird eye view of the outstanding ruins of the nymphaeum of the sanctuary of Apollo. Teams at work. 


\subsection{Survey planning}

The three areas respond to partly different issues to be dealt with, because of their own historical stratified nature, their spatial dimension and due to the scale of the archaeological intervention in which they are interested. In the direction of an integrated study concerning spatial, temporal and functional articulation about human settlement and related historical expressions during ages, the UAV photogrammetric approach has been tested as a rapid mapping system for a multi-scale documentation in integration with other innovative imaging solution (Trimble V10 rover) or a more consolidated ranging measurement (TLS).

First of all, an extension of the topographical network was achieved, as two of the excavation sites $(a, b)$ are located in an area of the city that had not yet been investigated in detail. The entire archaeological map of the ancient city (whose excerpt is in Figure 2) is based on terrestrial measurement systems with regard to ancient evidence, while it is derived from a traditional photogrammetric flight of the 90s for all natural elements and modern anthropization (D'Andria et. al. 2008). The measure of new vertexes has been realized with GPS/GNSS techniques, while the determination of the control points for the photogrammetric process and for the registration of the scans was carried out through the total station.

This last point was a planned decision precisely to increase the accuracy of the photogrammetric processes for areas shooted from very low UAV flights. In 2015, the Hierapolis site had already been affected by UAV flights and consequent generations of DSM and orthophotos of some main areas of major transformation of the city, for both massive excavations and restoration works (Chiabrando et al. 2017a). We cannot make direct comparisons with the 2015 flights, since at the time the images were acquired with a fixed wing drone at a higher altitude. We can compare the results with other experiences (Chiabrando et al. 2017c) and how we can see even in the next sections, the use of the total station allows to improve the accuracy of the final results.

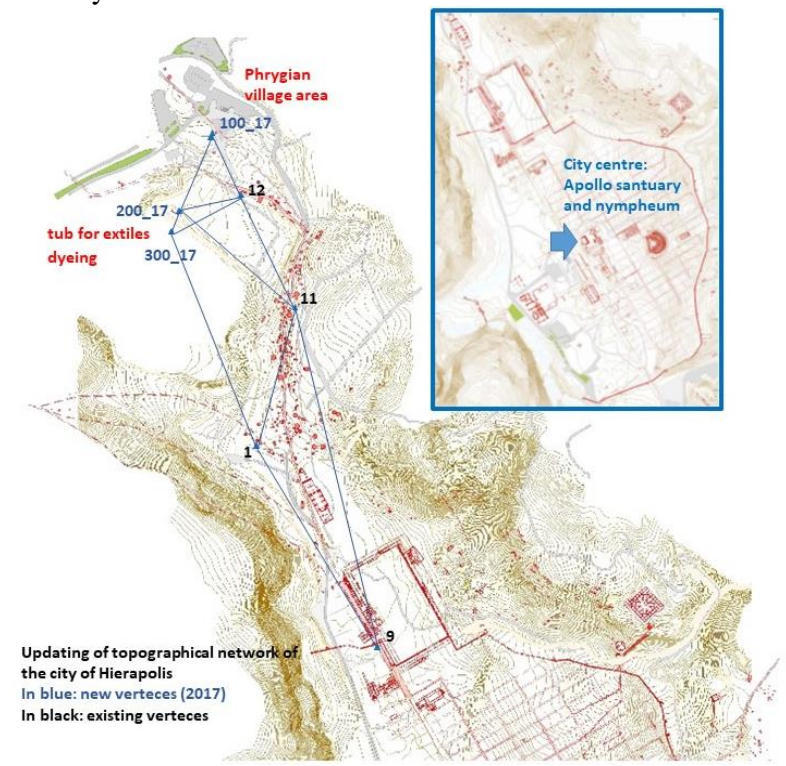

Figure 2. A part of the city map with the 2017 extension of the topographical network related to the location of the test sites.

\subsection{Selected equipments fitting survey aims}

In addition to the usual topographic equipment, the survey mission involved the popular Faro Focus ${ }^{3 \mathrm{D}}$ (http $/ / \mathrm{www}$.faro.com/products/3dsurveying/laser-scanner-faro-focus-3d), that was used to create accurate point clouds in order to use this data as ground truth for the various investigated diggings areas, allowing an evaluation of the image-based processes results.

Regarding the aerial flights, the choice of the UAV system fell on the Phantom DJI 4 (Fig.3), a radio controlled drone of the VTOL class (Vertical Take-off and Landing), able to acquire images in manual mode or following predefined flight plans. The drone is equipped with a GPS/GNSS receiver that allow to autonomously perform a pre-programmed flight and flight sensors, which allow to counteract the action of the wind in the absence of commands from the operator, improving stability. Moreover, the used platform was equipped by the "Obstacle Sensing System" that consisting of two optical sensors facing forward in order to avoid the obstacle. The camera is permanently attached to the drone and is kept perfectly balanced thanks to the 3-axis universal cardan joint (gimbal).

Essentially this drone is a low-cost commercial solution that responded to high portability project requirements, also respecting the overflight regulations required by Turkish institutions. Basically, the monitoring by low-altitude photogrammetric products of the excavation areas was substantial for us, which could be obtained by means of an economic drone that is easy and flexible to use.

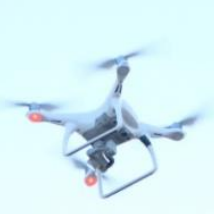

\begin{tabular}{|l|c|}
\hline payload (with batt.) & 1380 gr. \\
\hline Max speed & $\begin{array}{c}16 \mathrm{~m} / \mathrm{s} \text { (without } \\
\text { wind }\end{array}$ \\
\hline Camera sensor & $\begin{array}{c}1 / 2.3^{\prime \prime} \text { da } 12 \\
\text { Mpixels }\end{array}$ \\
\hline Camera lens & $\begin{array}{c}\text { FOV } 94^{\circ} 20 \mathrm{~mm} \\
\text { (35 mm format) }\end{array}$ \\
\hline
\end{tabular}

Figure 3. An image and some specs of the commercial low .cost solution: DJI phantom 4.

As is reported before, the other tested equipment was the Trimble V10 imaging Rover, which has been used in the project for one of the secondary purposes that is to share with the archaeologists not only the results but also the processes steps. Trimble V10 is an integrated camera system that precisely captures 60 megapixel $360^{\circ}$ digital panoramas provided by 12 calibrated sensors $(5 \mathrm{Mp}$ for each camera), integrated seamlessly with R10 GNSS receiver and total station positioning sensors (with Trimble equipment).

The instrument can be used in stand-alone mode or different image positions collection can be combined, and further adjusted starting from the prism or RTK receiver measurements and continue through the trimble business center software to derive the traditional photogrammetric model measures (digital plotting) or generate point clouds by exploiting image matching algorithms. (http://www.trimble.com/Survey/trimble-business-center.aspx) The first level of horizontal cameras are featured by landscape orientation with a field of view of $57.5^{\circ}$ (horizontal) $\mathrm{x} 43^{\circ}$ (vertical); 5 downward facing cameras have a portrait orientation with a field of view of $43^{\circ}$ (horizontal) x $57.5^{\circ}$ (vertical). The Figure 4 shows the total vertical field of view angle captured by panorama cameras, which is $93.1^{\circ}$; it is not very wide, and in fact the IR is equipped by tilt sensors, accelerometers and gyroscope that allow the tilt image collection up to $15^{\circ}$. In this paper however, the test has only experienced with vertical pole actuations.

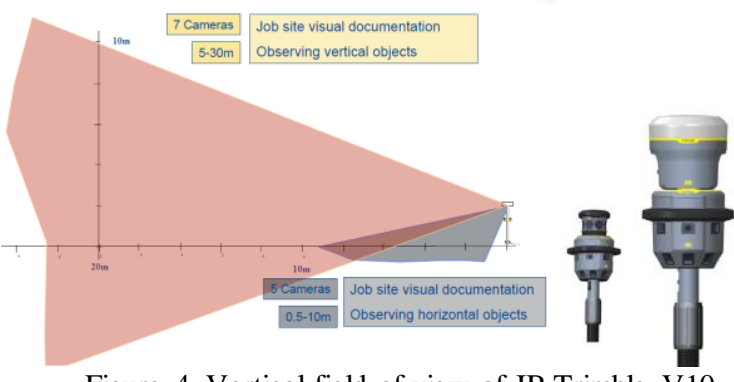

Figure 4. Vertical field of view of IR Trimble V10. 


\section{MULTI-SCALE UAV PHOTOGRAMMETRY FOR EXCAVATION SURVEY AND DOCUMENTATION}

\subsection{Two different flight plannings in (a) and (b) areas.}

The excavation (a) area, the Phrygian village, discovered following the construction of the reception and ticketing facilities, is the first so ancient frequented excavation area in Hierapolis for which at present it was not strictly necessary to define the relationship with the context. Thus it was a perfect opportunity to focus on the possibility that the photogrammetric UAV survey applied to the diggings area could make itself as competitive as possible to the more expensive and accurate Lidar survey.

A first flight with nadiral cameras (59 images) (Fig. 6, green images) has been performed to obtain a GSD (ground sampling distance) smaller than the centimeter $(0.007 \mathrm{~m})$ (Fig. 5) to which a flight of about $20 \mathrm{~m}$ altitude corresponded, considered limit due to the presence of a tree at the edges of the excavation. For the same reason the flight was conducted manually, and the main purpose was to produce a high resolution orthophoto. The photogrammetric processing has been performed using Pix $4 \mathrm{D}$ and the mean final accuracy on the GCPs (Ground Control Points) was $0.002 \mathrm{~m}$ (RMS error). To produce instead a very dense and accurate DSM, able to describe the details of the excavation in a way similar to TLS, a flight at a much lower altitude, $6 \mathrm{~m}$, with oblique shots, has been planned as well, and a close range photogrammetric acquisition has been carried out all around, at an average shooting distance of $3 \mathrm{~m}$ (Fig. 6, red/blue images).
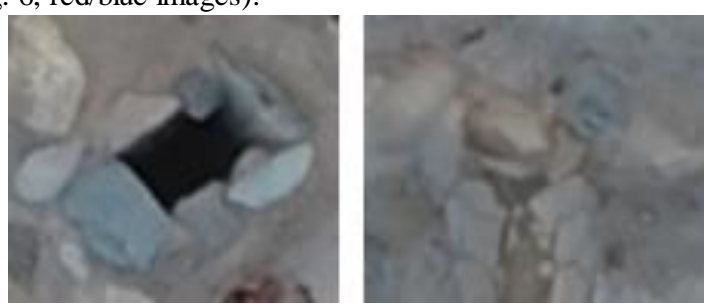

Figure 5. An excerpt of the $7 \mathrm{~mm}$ resolution orthophoto of the Phrygian village. Each stone is clearly readable.

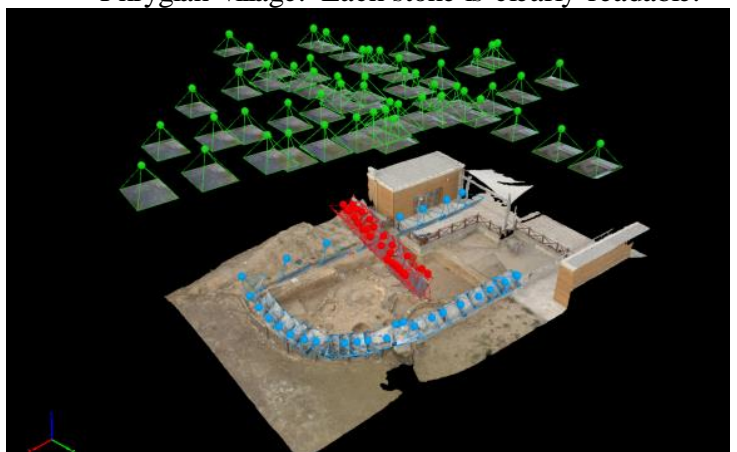

Figure 6. Nadiral set of strips in green (20 m altitude), oblique opposite strips in red ( $6 \mathrm{~m}$ from the ground), terrestrial strips in

light blue (almost $3 \mathrm{~m}$ distance) with dense cloud.

The ground control points (GPCs) were distributed at the edges of the excavation and inside and their coordinates were determined with total station; the processing was done again with the pix4D mapper software. The contemporary orientation of the overall strips has provided minimal errors as can be seen from Table 1.

\begin{tabular}{c|c|c|c|c|c|}
\hline & $\mathrm{n}$. & $\begin{array}{c}\text { X Error } \\
(\mathrm{RSM}) \\
{[\mathrm{m}]}\end{array}$ & $\begin{array}{c}\text { Y Error } \\
(\mathrm{RSM}) \\
{[\mathrm{m}]}\end{array}$ & $\begin{array}{c}\text { Z Error } \\
(\mathrm{RSM}) \\
{[\mathrm{m}]}\end{array}$ & $\begin{array}{c}\text { Medium error } \\
(\mathrm{RSM}) \\
{[\mathrm{m}]}\end{array}$ \\
\hline GCPs & 12 & 0,001 & 0,002 & 0,003 & 0,002 \\
\hline CPs & 4 & 0,002 & 0,001 & 0,007 & 0,004 \\
\hline
\end{tabular}

Table 1. Very high accuracy of the three types of oriented images blocks.
The strategy for planning the UAV survey in (b) area, the basin for textile dyeing, was decidedly different. Finding this excavation on the edge not only of the city, but also of the necropolis, and being built against the calcareous channel from which it supplied water (Fig.8), the contextualization through a flight at a discrete altitude was definitely appropriate. Again, given the lightness of the drone and being present a slight wind at the time of survey, it was opted again for a manual flight. Even in this case the shooting at higher altitude was nadiral $(40 \mathrm{~m})$ while the flight at low altitude $(10 \mathrm{~m})$ included nadiral and oblique images as well (Fig. 7). The excavation is particularly limited in size and the structure is very simple, but the terracotta paving slabs are decorated (Fig. 10, left), so that in this case a high resolution, accuracy and readability of the details was also sought- (Respectively 0.017 and $0.004 \mathrm{~m}$ GSD were planned for the two flights, Fig. 9).

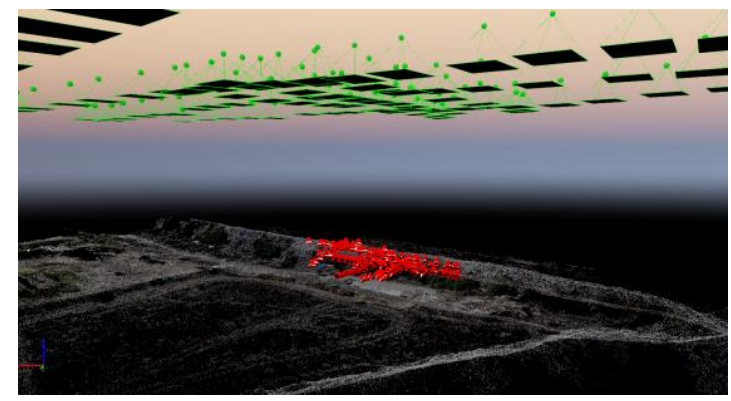

Figure 7. Oriented images showing 2 different flight planning strategies connected to the low $(10 \mathrm{~m})$ and high $(40 \mathrm{~m})$ allitude flights.

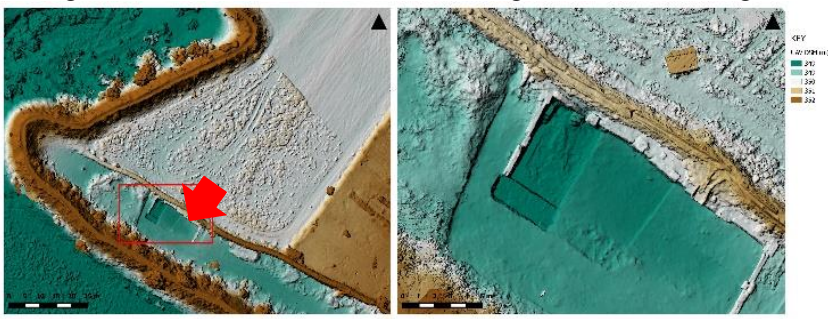

Figure 8. The impressive limestone channels, which flows sinuously north away from the city in the $0.017 \mathrm{~m}$ resolution DSM (left); the excavated basin in the high resolution DSM (right).

In this case also, the GCPs were determined through total station measurements and the residues on the coordinates of the points were particularly small, similarly to the results of the UAV survey in (a) area. Table 2 shows the accuracy results of the photogrammetric process, related to the two flights. In this case, the difference in altitude of the two flights is relevant, since each of them responds to a different need: to compare the position of the basin in an enlarged context, and the reading of the excavation site. It was therefore considered appropriate to segment and integrate the two DSMs, obtaining one unique multi-scale DSM. (Fig. 10, right).

\begin{tabular}{c|c|c|c|c|c|c|}
\hline & & $n$. & $\begin{array}{c}\text { X Error } \\
(\text { RSM }) \\
{[\mathrm{m}]}\end{array}$ & $\begin{array}{c}\text { Y Error } \\
(\mathrm{RSM}) \\
{[\mathrm{m}]}\end{array}$ & $\begin{array}{c}\text { Z Error } \\
(\mathrm{RSM}) \\
{[\mathrm{m}]}\end{array}$ & $\begin{array}{c}\text { Medium } \\
\text { error } \\
(\mathrm{RSM}) \\
{[\mathrm{m}]}\end{array}$ \\
\hline $\begin{array}{c}40 \mathrm{~m} \\
\text { altit. }\end{array}$ & $\mathrm{GCP}$ & 20 & 0,005 & 0,006 & 0,004 & 0,005 \\
\cline { 2 - 7 } & $\mathrm{CP}$ & 6 & 0,004 & 0,007 & 0,008 & 0,006 \\
\hline $\begin{array}{c}20 \mathrm{~m} \\
\text { altit. }\end{array}$ & $\mathrm{GCP}$ & 11 & 0,001 & 0,001 & 0,001 & 0,001 \\
\cline { 2 - 7 } & $\mathrm{CP}$ & 4 & 0,001 & 0,002 & 0,002 & 0,0016 \\
\hline
\end{tabular}

Table2. Very similar accuracy results for the different altitude flights. 

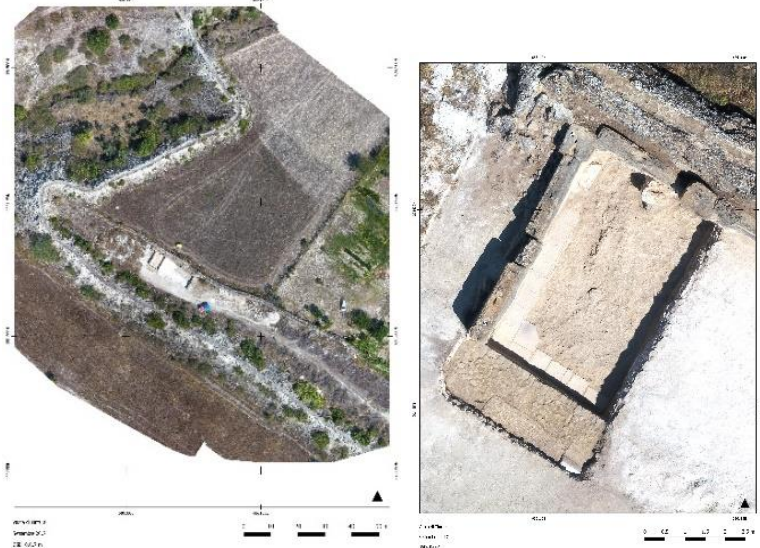

Figure 9. (left) $0.017 \mathrm{~m}$ per pixel orthophoto showing the two parallel channels flowing to north. (right) the $0.004 \mathrm{~m}$ resolution orthophoto of the basin.

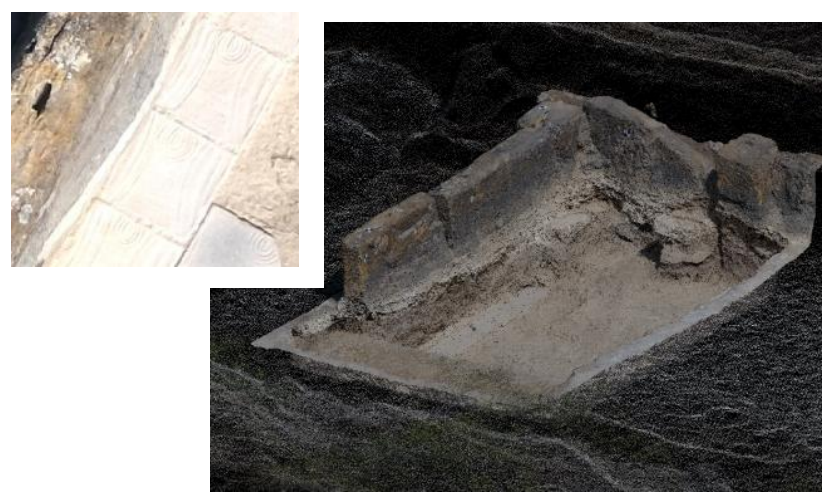

Figure 10. (left) The terracotta paving decorated slabs (from 4 $\mathrm{mm}$ resolution orthoimage) (right) $\mathrm{A} 3 \mathrm{D}$ view of the multiscale integrated DSM.

The common strategy to these tests consisted in generating a Lidar cloud that could have the function of controlling the general accuracy of DSMs derived from low-level flights. The wellestablished workflow, which has provided the best results also on other occasions (Chiabrando et al. 2017c) was to record Lidar scans initially by shape (cloud-to-cloud), using ICP (Iterative Closest Points) algorithms for the first registration, and then measure the control points on the complete scan for georeferencing and evaluating the accuracy. In addition, the targets for the registration of the Lidar clouds were obviously surveyed by total station and the processing has been performed using Faro Scene software. Figure 11 and table 3 report the results for the two excavation areas (a) and (b).

Having the Lidar clouds as ground truth, the DSMs from UAV were compared with them. Segmenting a sample area transverse to the excavation, with some surprise in the village area, a deviation towards the edges of the DSM up to $4 \mathrm{~cm}$ has been ascertained (Fig. 12), while a good alignment is found in the central part. This means that the compact camera of the DJI phantom 4 drone, characterized by a low focal length, produces high distortions.

Further, the presence of a tree near the excavation did not allow to plan parallel and transversal strips, which usually tighten and improve the bundle adjustment of the images orientation. It is therefore highly recommended to thicken the control points (for a very small area of 0.15 hectares, 12 points of control were few).

In the dyeing basin, the segmentation of a sample area on the terracotta slabs of the flooring gave better results, showing a deviation of a few millimeters on the slabs, and up to $2 \mathrm{~cm}$ for points at a higher level, which can also be considered noise (Fig.13).
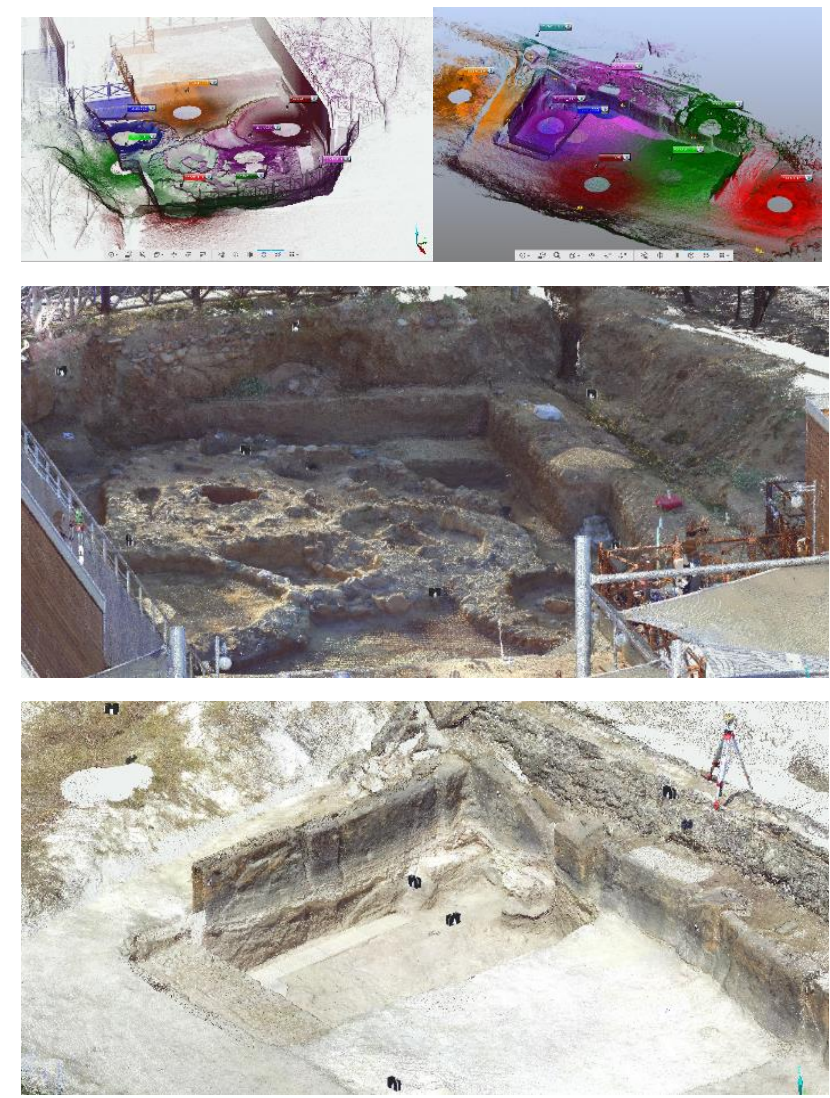

Figure 11. (above) Scans positions in the two test areas; (below) dense clouds of test areas.

\begin{tabular}{|l|c|c|c|c|}
\hline & \multicolumn{3}{|l|}{ cloud to cloud } & target based \\
\hline Sites and n. scans & $\begin{array}{c}\text { average tension on } \\
\text { scan points (mm) }\end{array}$ & $\begin{array}{c}\text { average tension on } \\
\text { scan points }(<4 \\
\mathrm{mm})\end{array}$ & $\begin{array}{c}\text { average } \\
\text { tension on } \\
\text { targets (mm) }\end{array}$ & $\begin{array}{c}\text { standard } \\
\text { deviation } \\
(\mathrm{mm})\end{array}$ \\
\hline $\begin{array}{l}\text { Necropolis village } \\
\text { (8 scans) }\end{array}$ & 2.4 & $66 \%$ & 5.48 & 1.44 \\
\hline Dyeing basin (9 scans) & 3.1 & $60 \%$ & 4.32 & 0.29 \\
\hline
\end{tabular}

Table 3. Usual high accuracy evaluated for TLS results on CH.

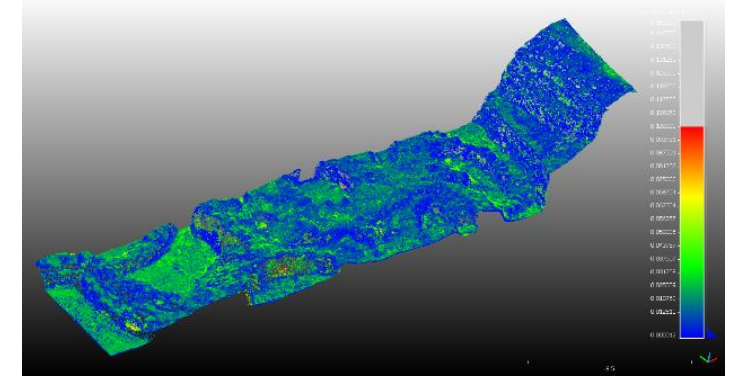

Figure 12. The UAV cloud compared to the LiDAR cloud. A sizeable $(4 \mathrm{~cm})$ misalignment is shown in green points.

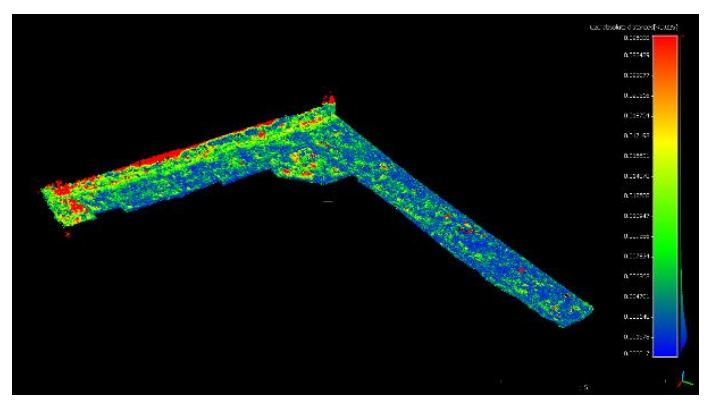

Figure 13. Slight difference (1-3 $\mathrm{mm})$ between UAV and LiDAR clouds on the terracotta slabs 


\section{HIGH-SCALE DATA FOR MULTI-PURPOSES 3D MODELS IN THE APOLLO NYNPHAEUM}

The 3D survey and modelling of a large monumental complex such as the nymphaeum of the sanctuary of Apollo is certainly interesting and complex. In addition to the reasons for knowledge of the successive layers of use and transformation of ancient public spaces already mentioned in the test cases paragraph, there is even a more general scope of the study of ancient seismic events and the decisions to be taken for the safety of modern visitors. In essence, the $3 \mathrm{D}$ modelling products will have to be useful to many different working groups, from archaeologists, to engineers who deal with geophysical surveys and stability of structures, restorers and architects who deal with the musealization of ancient evidence.

Substantially, a way of integration and/or fusion of LiDAR techniques with close range and UAV photogrammetry have been chosen.

The 45 scans carried out to completely cover the mighty walls of the nymphaeum and the adjacent spaces, were grouped into 3 blocks of scans; according to the strategy already adopted, the clouds were recorded in a first phase using the cloud-to-cloud method, and subsequently georeferenced and evaluated with a high number of control points (29). (Fig. 14)

Table 4 shows the excellent level of registration obtained. To check the actual quality of the general geometric content as well, the clouds were imported into the 3DReshaper by Technodigit (Hexagon) modelling software, and thin section profiles were extracted into sample portions where the adjacent scans are covered; this check led to finding $3 \mathrm{~mm}$ of maximum difference between the scans (Fig. 15).

Given the eminent size of the masonry that reaches ten meters in height and the significant planimetric extension of the area of interest, for the UAV photogrammetry survey, the GSD has been predefined around $1 \mathrm{~cm}$, from which a height of overflight equal to about $25 \mathrm{~m}$ has been derived. The area is free of obstacles at this height, so the flight planning has provided for nadiral and oblique strips, sufficiently oriented in favor of the vertical development of the walls, intertwined with each other at $90^{\circ}$ both for the layout of the $\mathrm{C}$ walls and to strengthen the processing of the photogrammetric block, achieved using Photoscan software. 241 images of the 242 acquired were processed; the control points were always measured using the total station to make the generated point cloud more accurate, and the result of the photogrammetric process yields average results around one and a half centimeters, as shown in Table 4 .

Figure 16 shows the distribution of residuals on GCPs and CPs. The reference system adopted for all the elaborations is the cartographic one (all the processings are carried out bringing a truncation to the coordinates of the points, while the nymphae um, following the orientation of the regular road system of the city is arranged parallel to the plateia on which it overlooks. (Fig 17)

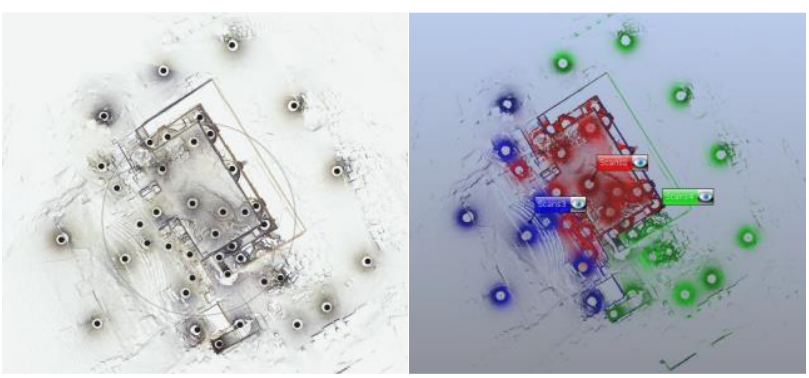

Figure 14. Scan positions in the nymphaeum area and their grouping in three blocks to enhance processing.

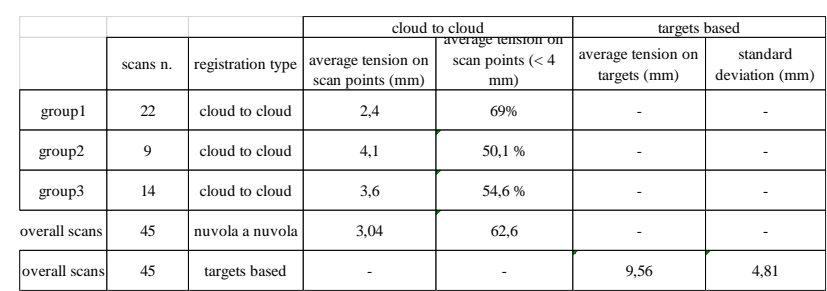

Table 4. Comparison of residuals among different groups of scans and different types of registration.

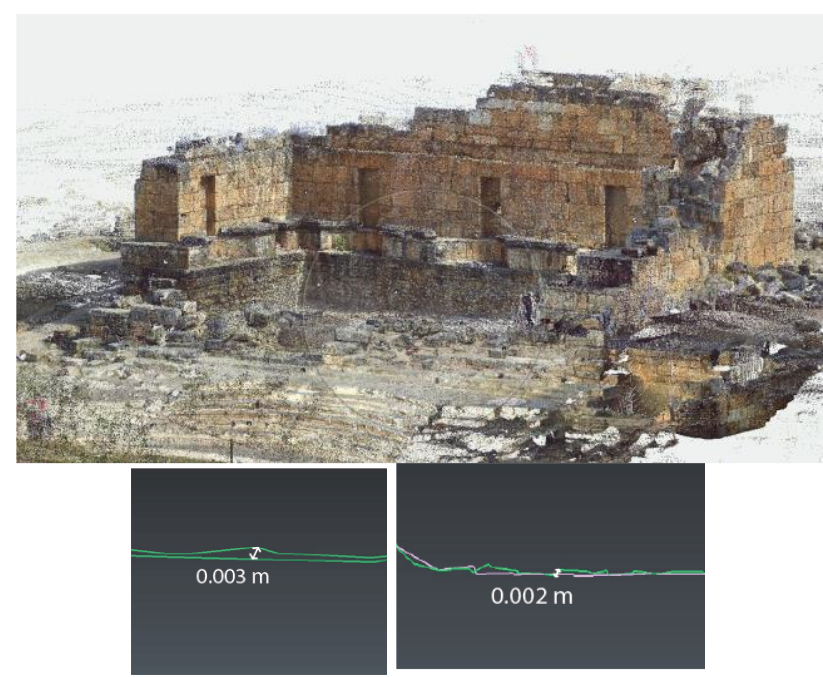

Figure 15. The final overall points cloud $(25 \mathrm{ml}$ points $)$ and (below) very low distances among profiles extracted from

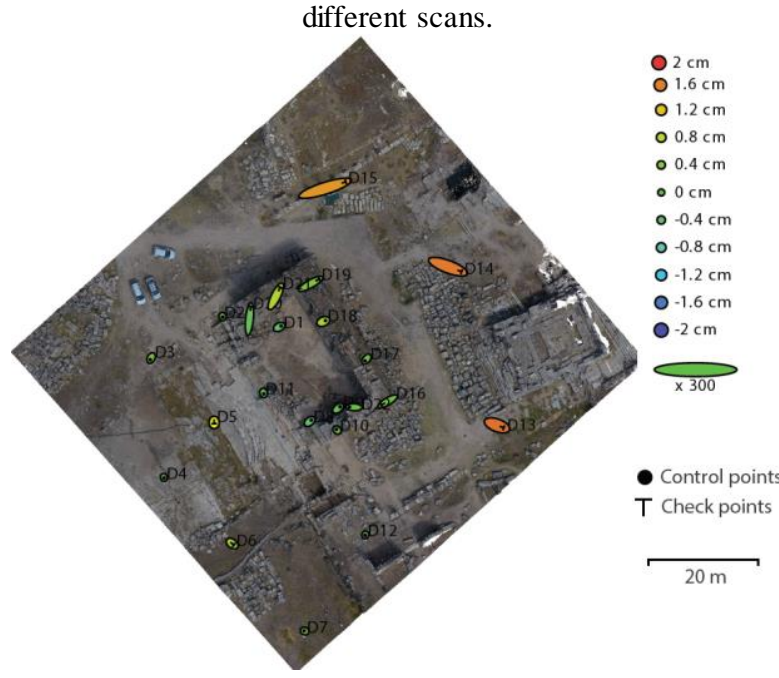

Figure 16. Spatial distributions of residual on GCPs and CPs (under 0.01 meters on the building and up to 0.015 in

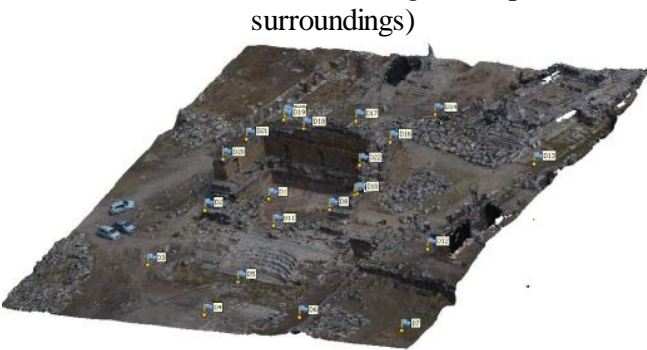

Figure 17. the overall high-quality nymphaeum area UAV cloud in a 3D view with GCPs distribution 


\subsection{Integrated modelling of ancient masonry: UAV and terrestrial range-based clouds fusion.}

Very often the UAV clouds are integrated into the process of buildings modeling for their effective point of view, composing the high areas of the model of the object that are usually very incomplete in the terrestrial Lidar models. In the case of the walls of the nymphaeum of Hierapolis, a fusion strategy was experimented that provides results of a higher quality than the simple union of multi-resolution data to obtain a multiscale model.

Figure 18 shows the segmentation of a portion of the nymphae um located in the northern corner of the scene front, equally segmented from the aerial cloud and the LiDAR cloud: the first consists of 330.660 points, while the terrestrial consists of 2.990.102 points.

An interesting tool offered by the latest version of the Photoscan software, is the ability to import Lidar clouds and integrate them with photogrammetric clouds to improve the generation of the meshes, which become necessarily much more detailed thanks to the resolution of the LiDAR data. This test has been experimented by extracting the LiDAR clouds from the 3DReshaper modeling software, which previously recorded the point cloud normal and allowed a leaner processing. The results of the test are shown in the figure 18 (below), which show a continuous triangulated surface, in which the aerial and terrestrial points of view have been merged, and therefore allows in a complete manner to analyze elements of high detail such as the wall texture (Fig.19).
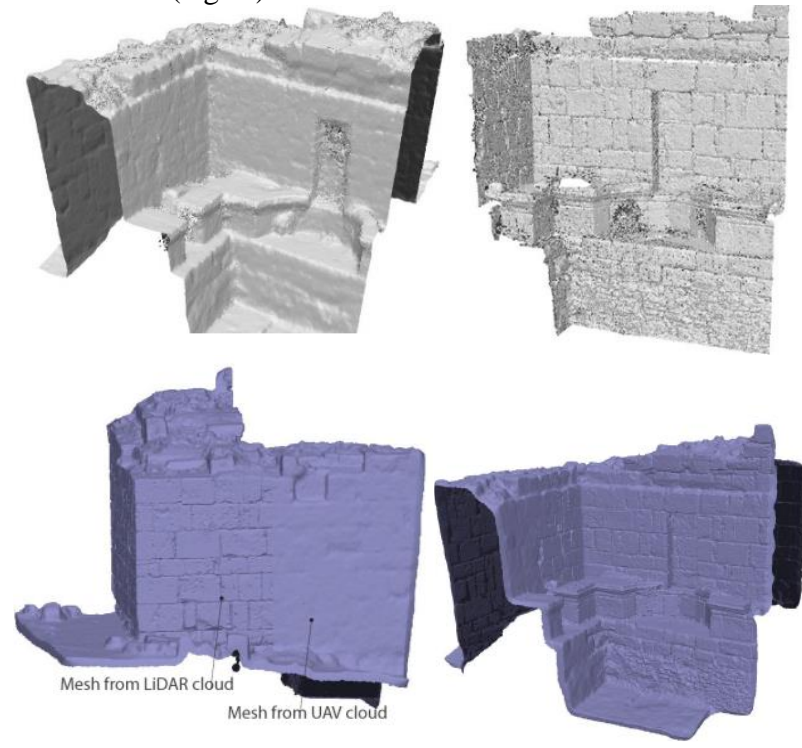

Figure 18. (above) Visual comparison among segmented clouds (UAV: 330.660 p.; LiDAR 2.990 .102 p.). (below) comparison among meshes and final mesh from integrated clouds.

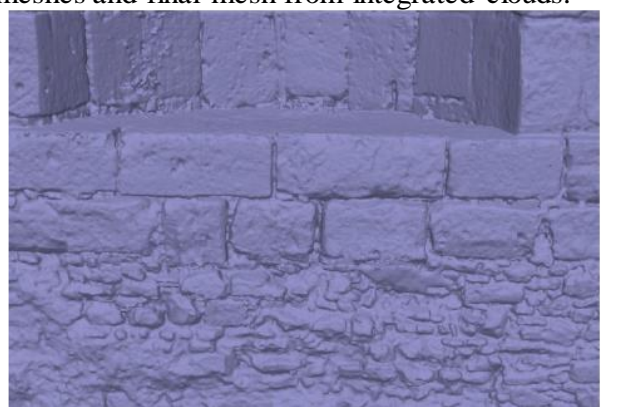

Figure 19. Ability of reading the wall texture in the final mesh surface, derived from LiDAR and UAV data.

\subsection{Panoramic survey potentialities: results and usability of V10 imaging rover}

Regarding the test survey using the IR V10, the excavation area of the nymphaeum basin and the imposing front of the scene were chosen. Given the usual complexity of working on ancient walls of particular articulation and decay, we chose to perform an experimentation that aimed at the basic results, to evaluate the effective possibility of modelling and plotting the walls following a simple workflow. Inside the basin, a series of panoramic images have been acquired from several positions, and the results of this first presented test are derived from using only 4 stations and only with vertical position of the pole, despite the reduced distances have not allowed to survey the high portions of the masonry.

The cameras positions were all measured with a total station using the prism mounted above them; this possibility allows providing a first solution of mutual position of the stations, which the Trimble Business Center software is able to adjust after the collimation of a certain number of control points; in the present case a dozen.

As a result of the positions adjustment and the images orientation, the evaluation of the position of a series of control points measured with both systems, the IR V10 and the classical topographic technique, provided residuals of the order of a pair of centimeters, obtaining results comparable to other tests appeared in the literature and already mentioned.

Once it was established that the photogrammetric model of the IR V10 was correct, the automatic generation of a points cloud of the inside facade of the nymphaeum was experimented; although the calculated stations were only 4 , the image matching algorithm was able to find about 400 tie points and the cloud of figure 20 (above) has been calculated.

Both the surfaces at the distance that respects the ratio 1: 4 between the base line between near station and distance between sensor and object, typical of classical photogrammetry and recommended by Trimble guidelines, both more distant surfaces have been detected in the automatically generated cloud.

Based on the same criterion of respecting the basic ratio 1:4, different plotting strategies have been tested: figure 20 shows 3D polylines that follow the limits of the calcareous block of the masonry, the detection of a plan for each block, or the more rapid detection of a single plan for the plotting of an entire architectural plan.

\section{CONCLUSION AND FUTURE PERSPECTIVES}

A general overview of the achieved aerial and terrestrial products with the connected accuracy have been analysed in the paper in order to define, according to the characteristic of each studied area the most suitable approach for correctly support the largescale archaeological documentation and monitoring.

The aerial acquisitions were achieved considering different consolidated and experimental procedures: flight at different heights and different camera orientation and configuration were used and tested. One of the lessons learned is that by realizing the measurement of control points using the total station, residuals on control points obtainable are very small and therefore the models are more accurate. Furthermore, it's one more time clear that the geometry organization of the planned strips during flight planning is essential to obtain excellent accuracies.

On the one hand, the UAV photogrammetric approach from medium-high flight elevation contribute to the cartographic updating, to the study of the archaeological landscape in its transformation. The integration among UAV and LiDAR data, in well-known and consolidated ways or using the recent method of generating mesh surfaces that exploit the collaboration of the two 
different types of clouds, would seem increasingly promising. That is true mainly for what concerns the micro-topographic conformation, the morphological and the geological aspects of the Hierapolis articulated context founded on a calcareous shelf, rich in springs emerging from subterranean galleries and affected by destructive seismic activities since ancient age.

Surely, all many kinds of models are very useful even when the archaeologist is not on the excavation; they can assure not only results sharing but even processes sharing. Regarding the IR V10 abilities, they are surely interesting, but many knowledges on photogrammetric workflow are requested to the operator.

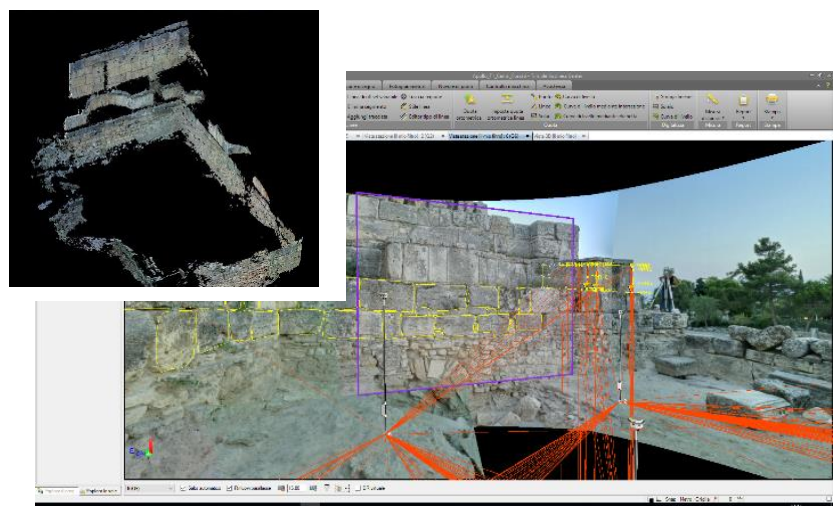

Figure 20. (above) Automatically generated point clouds using 4 IR V10 stations. (below) manual plotting using 2D and 3D strategies.

\section{ACKNOWLEDGEMENTS}

The study activities on rapid mapping system applications aimed at surveying and modelling archaeological excavated areas are involved in PRIN 2015 "Archeology of urban landscapes in Asia Minor between late Hellenism and Byzantine age. Multidisciplinary approaches to the study of Hierapolis in Phrygia", national principal investigator G. Semeraro, local resp. Spanò. The authors would like to warmly thank the students A. Rabbia and A. Trovato, who have collaborated in the processings.

\section{REFERENCES}

Adamopoulos, E., Tsilimantou, E., Keramidas, V., Apostolopoulou, M Karoglou, M., Tapinaki, S., Ioannidis C., Georgopoulos A. \& Moropoulou, A. 2017. Multi-sensor documentation of metric and qualitative information of historic stone structures. In ISPRS Annals of Photogrammetry, Remote Sensing and Spatial Information Sciences, IV-2/W2, 1-8. https://doi.org/10.5194/is prs-annals-IV-2-W2-1-2017

Baiocchi V., Giammarresi V., Ialongo R., Piccaro C., Allegra M, Dominici D., 2017 The survey of the Basilica diCollemaggio in L'Aquila with a system of terrestrial imaging and most proven techniques, European Journal of Remote Sensing, 50:1,237-253, DOI: 10.1080/22797254.2017.1316523

Balletti C., Guerra F., Scocca V., Gottardi C., 2015, 3D integrated methodologies for the documentation and the virtual reconstruction of an archaeological site, in ISPRS International Archives of the Photogrammetry, Remote Sensing and Spatial Information Sciences XL-5/W4, doi:10.5194/isprsarchives-XL-5-W4-215-2015

Cera, V. and Campi, M., 2017. Evaluating the potential of imaging rover for automatic point cloud generation, ISPRS International Archives of the Photogrammetry, Remote Sensing and Spatial Information Sciences, XLII2/W3, 147-154, https://doi.org/10.5194/is prs-archives-XLII-2-W3-147-2017, 2017.

Chiabrando, F., D’Andria F., Sammartano, G., Spano, A., 2017a. UAV photogrammetry for archaeological site survey. $3 \mathrm{~d}$ models at the Hierapolis in Phrygia (Turkey). In: Virtual Archaeology Review, 8(16): 83-96. doi.org/ 10.4995/var.2017.5961

Chiabrando, F., Lingua, A., Maschio, P., and Teppati Losè, L. 2017b. The influence of flight planning and camera orientation in UAVs photogrammetry. A test in the area of rocca san silvestro (LI), Tuscany, ISPRS International
Archives of the Photogrammetry, Remote Sensing and Spatial Information Sciences, XLII-2/W3, 163-170, https://doi.org/10.5194/is prs-archives-XLII2-W3-163-2017

Chiabrando, F., Naretto, M., Sammartano, G., Sambuelli, L., Spanò, A., \& Teppati Losè, L., 2017c. The 4Dilan Project (4Th Dimension in Landscape and Artifacts Analyses). ISPRS - International Archives of the Photogrammetry, Remote Sensing and Spatial Information Sciences, XLII5/W1, 227-234. https://doi.org/10.5194/is prs-archives-XLII-5-W1-227-2017 D'Andria F., Scardozzi G., Spanò A., 2008, Atlante di Hierapolis di Frigia, EGE Yayinlari, Istanbul.

Dell'Unto, N. (2014). The use of 3D models for intra-site investigation in archaeology. 3D Recording and Modelling in Archaeology and Cultural Heritage: Theory and Best Practices, 24(10), 1407-1408. https://doi.org/10.1177/0959683614545031

Drap P., Merad D., Seinturier J., Boï J. M., Peloso D., Vannini G., Nucciotti M.,Pruno E., 2012. An Information Systemfor Medieval Archaeology Based on Photogrammetry and Archaeological Database: The Shawbak Castle Project, In Euromed 2012.

Feifei, X., Zongjian, L., Dezhu, G., Hua, L., 2012. Study on construction of 3D building based on UAV images. In ISPRS International Archives of the Photogrammetry, Remote Sensing and Spatial Information Sciences, pp. 469473.

Fangi, G., 2007. The Multi-image spherical Panoramas as a tool for Architectural Survey. In: Int. Arch. of Photogrammetry, Remote Sensing and Spatial Information Sciences, XXXVI-5/C53.

Fangi, G., Clini, P., Fiori, F., 2008. Simple and quick digital technique for the safeguard of Cultural Heritage. The Rustem Pasha mosque in Istanbul. In: DMARC 4 -Digital Media andits Applications in Cultural Heritage, pp. 209217.

Fiorillo, F., Fernandez-Palacios, B. J., Remondino, F., Barba, S., 2013. 3D Surveying and modelling of the Archaeological Area of Paestum, Italy. In: VirtualArchaeology Review, 4(8), pp. 55-60.

Georgopoulos, A., Oikonomou, C., Adamopoulos, E., \& Stathopoulou, E. K. (2016). Evaluating unmanned aerial platforms for cultural heritage large scale mapping. ISPRS - International Archives of the Photogrammetry, Remote Sensing and Spatial Information Sciences, XLI-B5, 355-362. $\mathrm{https}$ ://doi.org/10.5194/is prsarchives-XLI-B5-355-2016

Höhle, J., 2008. Photogrammetric measurements in oblique aerial images. Photogrammetrie, Fernerkundung, Geoinformation, (1), pp. 7-14.

Katsianis M., Tsipidis S., Kotsakis K., Kousoulakou A., 2008. A 3D digital workflow for archaeological intra-site research using GIS, Journal of Archaeological Science 35 pp. 655-667.

Ruiz Sabina, J. Á., Gallego Valle, D., Peña Ruiz, C., Molero García, J. M., \& Gómez Laguna, A. (2015). Aerial Photogrammetry by drone in archaeological sites with large structures. Methodological approach and practical application in the medieval castles of Campo de Montiel. Virtual Archaeology Review, 6(13), 5. https://doi.org/10.4995/var.2015.4366

Sauerbier, M., Eisenbeiss, H., 2010. UAVs for the documentation of archaeological excavations. In: IAPRS\&SIS, Vol. 38(5), Newcastle upon Tyne, UK.

Sammartano G., 2018, Suitability of 3D dense models for rapid mapping strategies on $\mathrm{CH}$ documentation and conservation, doctoral thesis, Politecnico di Torino

Semeraro G., 2012, Archaeology of the cult in the sanctuary of Apollo in Hierapolis, in Guizzi F (ed.), Fra il Meandro e il Lico. Archeologia e storia in un paesaggio anatolico. Atti del Worshop Internazionale, Università 'La Sapienza- Roma', 30 Marzo 2012, Scienze dell'Antichità 20.2, ISSN 1123 5713, ISBN 978-88-7140-586-5, pp. 11-29

Szeliski, R., 2010. Computer vision: algorithms and applications. Springer Science \& Business Media.

TucciG., Visintini D., Bonora V., Parisi E., 2018, Examination of indoor mobile mapping systems in a diversified internal/external test field, Applied Science. 2018, 8, 401; doi:10.3390/app8030401

Xiao, J., Gerke, M., Vosselman, G. (2012). Building extraction from oblique airborne imagery based on robust façade detection. ISPRS Journal of Photogrammetry and Remote Sensing, 68, 56-68. http://doi.org/10.1016/j.is prsjprs.2011.12.006 